\title{
AVALIAÇÃO DA INFLUÊNCIA DAS CÉLULAS DE BACILLUS MEGATERIUM NA DETERMINAÇÃO DO COEFICIENTE DE TRANSFERÊNCIA DE OXIGÊNIO EM CULTIVO SUBMERSO
}

\author{
G. C. LORENZINI ${ }^{1}$, D. J. L. FACCIN ${ }^{1}$, M. A. Z. AYUB ${ }^{2}$, N. S. M. CARDOZO ${ }^{1}$ e R. RECH ${ }^{2}$ \\ ${ }^{1}$ Universidade Federal do Rio Grande do Sul - Departamento de Engenharia Química \\ ${ }^{2}$ Universidade Federal do Rio Grande do Sul - Instituto de Ciência e Tecnologia de Alimentos \\ E-mail para contato: debora@enq.ufrgs.br
}

\begin{abstract}
RESUMO - O coeficiente volumétrico de transferência de oxigênio $\left(k_{L} a\right)$ é um critério importante no dimensionamento e escalonamento de biorreatores aeróbios. Esse parâmetro é afetado por diversos fatores, como as condições operacionais e as propriedades do meio de cultivo. No presente trabalho, procurou-se identificar se a biomassa viável e a concentração dessa afetam os valores de $k_{L} a$ em um cultivo de Bacillus megaterium. Para isso, realizou-se um cultivo batelada em biorreator do tipo tanque agitado, mantendo-se constantes as condições de temperatura, aeração e velocidade de agitação. Os valores de $\mathrm{k}_{\mathrm{L}}$ a foram determinados periodicamente através do método dinâmico. $\mathrm{O}$ valor de $\mathrm{k}_{\mathrm{L}} \mathrm{a}$ não foi significativamente influenciado pela presença de biomassa, conforme confirmado por análise de variância. Esse resultado permite que seja feita a determinação prévia do valor de $k_{L} a$ em biorreator sem células e, assim, elimina-se a problemática da medição do coeficiente durante $o$ cultivo para o sistema estudado.
\end{abstract}

\section{INTRODUÇÃO}

A produção de poli(3-hidroxibutirato), ou PHB, é um processo biotecnológico de interesse comercial. Esse poliéster é um polímero biodegradável e biocompatível produzido a partir de fontes renováveis, com características promissoras para a substituição, puro ou com inserção de outros monômeros, de polímeros oriundos do petróleo (Verlinden et al., 2007). O PHB é produzido naturalmente por diferentes microrganismos, incluindo a Bacillus megaterium, uma bactéria estritamente aeróbia, que aceita uma variedade de carboidratos como fonte de carbono, cresce em uma faixa relativamente ampla de temperaturas e possui crescimento acelerado (Reyes et al., 1997). No entanto, a síntese de PHB por B. megaterium depende de condições específicas de disponibilidade de oxigênio no cultivo. Enquanto altas concentrações do gás inibem a síntese de PHB, uma menor disponibilidade dele favorece a produção do biopolímero, o qual possuiria função de reserva de carbono e fonte energética da célula (Macrae e Wilkinson, 1958). Entretanto, uma grande limitação de oxigênio pode resultar na esporulação das bactérias, havendo o consumo de PHB por elas (Wu et al., 2001).

Os cultivos aeróbios em larga escala ocorrem geralmente em biorreatores do tipo tanque 


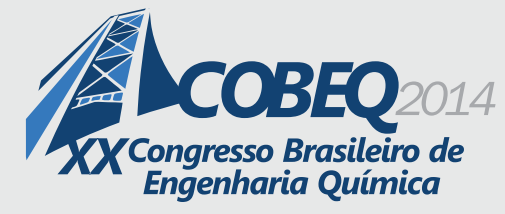

19 a 22 de outubro de 2014

Florianópolis/SC

agitado (STR), em meio líquido, envolvendo um sistema trifásico sólido-líquido-gasoso. Nesses, o fator limitante decisivo é o fornecimento de oxigênio ao meio, devido à sua baixa solubilidade em água (Borzani et al., 2001). Um dos principais parâmetros para quantificar a eficiência de transferência de oxigênio em um biorreator aeróbio é o coeficiente volumétrico de transferência de oxigênio $\left(k_{L} a\right)$, que é importante para o escalonamento, dimensionamento e operação deste tipo de biorreator. $\mathrm{O} k_{L} a$ é afetado por diversos fatores, entre eles, as condições operacionais e as propriedades do meio de cultivo, havendo diversos estudos nesse sentido (Garcia-Ochoa e Gomez, 2009). Há, porém, estudos na literatura provando que não apenas esses fatores influenciam o valor do $k_{L} a$, mas também a presença e a concentração de biomassa (Galaction et al., 2003).

Os efeitos possíveis da biomassa no $k_{L} a$ estudados na literatura são (a) a alteração de propriedades do meio (viscosidade, tensão superficial, etc.); (b) a presença física das células como partículas sólidas, que podem bloquear a interface gás-líquido ou provocar o "efeito bola de neve", no qual, quanto mais células vão sendo adsorvidas nessa interface, mais ela se torna móvel; e (c) a influência da respiração celular das células acumuladas na interface, quantificada por um fator de aumento $E$ do $k_{L} a$ (Ju e Sundararajan, 1994). Através dos trabalhos disponíveis, percebeu-se que muitos desses efeitos apontam para direções opostas, podendo ocorrer um aumento ou um decréscimo do $k_{L} a$ com a biomassa. Ainda, detectou-se a carência de estudos que avaliem experimentalmente o comportamento do $k_{L} a$ com a concentração celular de biomassa viável.

Pelos motivos acima expostos, e em vista da importância da transferência de oxigênio para a otimização da produção de PHB por B. megaterium, que é um microrganismo de interesse por suas características de crescimento e produtos, o presente trabalho estuda se há influência da presença e da concentração da biomassa viável no $k_{L} a$ durante um cultivo dessa bactéria.

\section{MATERIAIS E MÉTODOS}

\subsection{Microrganismos e meio de cultura}

O microrganismo utilizado foi Bacillus megaterium DSMZ $32^{\mathrm{T}}$, mantido congelado a $-18{ }^{\circ} \mathrm{C}$ em solução crioprotetora $(20 \%$ em volume de glicerol), com estoque renovado a cada 6 meses. As bactérias foram reativadas em meio mineral idêntico ao utilizado no cultivo, durante $18 \mathrm{~h}$, em estufa incubadora rotatória, a $160 \mathrm{rpm}$ e $30{ }^{\circ} \mathrm{C}$. Foi realizado o escalonamento, transferindo-se $2 \%$ (em volume) do pré-inóculo a outro frasco, mantido por aproximadamente $5 \mathrm{~h}$ nas mesmas condições.

Utilizou-se o meio mineral proposto por Wang e Lee (1997) composto por $\mathrm{KH}_{2} \mathrm{PO}_{4}, 1,5$ $\mathrm{g} \cdot \mathrm{L}^{-1} ; \mathrm{Na}_{2} \mathrm{HPO}_{4} \cdot 12 \mathrm{H}_{2} \mathrm{O}, 9 \mathrm{~g} \cdot \mathrm{L}^{-1} ; \mathrm{MgSO}_{4} \cdot 7 \mathrm{H}_{2} \mathrm{O}, 0,2 \mathrm{~g} \cdot \mathrm{L}^{-1} ; \mathrm{CaCl}_{2} .2 \mathrm{H}_{2} \mathrm{O}, 0,01 \mathrm{~g} \cdot \mathrm{L}^{-1}$; ácido cítrico, $0,1 \mathrm{~g} \cdot \mathrm{L}^{-1}$; acrescido de $1 \mathrm{~mL} \cdot \mathrm{L}^{-1}$ de solução de micronutrientes $\left(\mathrm{FeSO}_{4} 7 \mathrm{H}_{2} \mathrm{O}, 20 \mathrm{~g} \cdot \mathrm{L}^{-1}\right.$; $\mathrm{MnCl}_{2} \cdot 4 \mathrm{H}_{2} \mathrm{O}, 0,03 \mathrm{~g} \cdot \mathrm{L}^{-1} ; \mathrm{H}_{3} \mathrm{BO}_{3}, 0,3 \mathrm{~g} \cdot \mathrm{L}^{-1} ; \mathrm{CuSO}_{4} \cdot 5 \mathrm{H}_{2} \mathrm{O}, 0,01 \mathrm{~g} \cdot \mathrm{L}^{-1} ; \mathrm{CoCl}_{2} \cdot 6 \mathrm{H}_{2} \mathrm{O}, 0,2 \mathrm{~g} \cdot \mathrm{L}^{-1}$; $\left.\left(\mathrm{NH}_{4}\right)_{6} \mathrm{Mo}_{7} \mathrm{O}_{24} \cdot 4 \mathrm{H}_{2} \mathrm{O}, 0,03 \mathrm{~g} \cdot \mathrm{L}^{-1} ; \mathrm{ZnSO}_{4} \cdot 7 \mathrm{H}_{2} \mathrm{O}, 0,03 \mathrm{~g} \cdot \mathrm{L}^{-1} ; \mathrm{NiSO}_{4} \cdot 7 \mathrm{H}_{2} \mathrm{O}, 0,03 \mathrm{~g} \cdot \mathrm{L}^{-1}\right)$. Foram utilizados $16 \mathrm{~g} \cdot \mathrm{L}^{-1}$ de sacarose como fonte de carbono e $2 \mathrm{~g} \cdot \mathrm{L}^{-1}$ de sulfato de amônio como fonte 


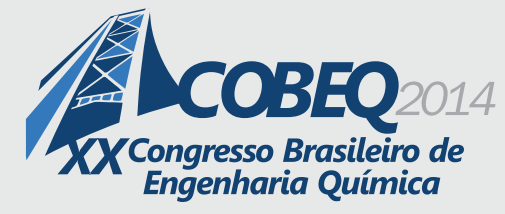

de nitrogênio. $\mathrm{O} \mathrm{pH}$ inicial foi ajustado para 7,0 através da correção com ácido $\left(\mathrm{H}_{3} \mathrm{PO}_{4} 2 \mathrm{M}\right)$ ou base $(\mathrm{NaOH} 2 \mathrm{M})$. Foram adotados os procedimentos e cuidados em relação à esterilização do conjunto.

\subsection{Procedimento experimental}

O cultivo batelada, com $12 \mathrm{~h}$ de duração, foi realizado através de duplicatas independentes entre si em biorreator de bancada tipo tanque agitado (STR) de $5 \mathrm{~L}$ (4 L de volume útil) BIOSTAT ${ }^{\circledR}$ B (Braun Biotech). O impelidor de aço inox é do tipo turbina com dois conjuntos de 6 pás planas. $\mathrm{O}$ biorreator está acoplado a uma unidade de controle e as variáveis controladas foram temperatura $\left(30^{\circ} \mathrm{C}\right)$ e velocidade do impelidor $(600 \mathrm{rpm})$. A taxa de aeração foi mantida constante em $4 \mathrm{~L} \cdot \mathrm{min}^{-1}(1 \mathrm{vvm})$. $\mathrm{O}$ ar, fornecido por compressor, foi injetado por aerador localizado abaixo do impelidor. Efetuou-se a injeção de antiespumante quando necessário e não houve controle de $\mathrm{pH}$ durante o cultivo. As medidas de percentual de saturação de oxigênio dissolvido $\left(p_{\mathrm{O} 2}\right)$ foram realizadas por eletrodo polarográfico InPro 6800/12/320 (Mettler-Toledo) conectado ao biorreator e previamente calibrado no meio de cultivo. Um computador foi conectado ao conjunto para a aquisição de dados, utilizando-se o software MATLAB (MathWorks) como interface.

\subsection{Análises}

Concentração de biomassa: As medidas de biomassa total $(X)$ foram determinadas, em duplicata, por medida de peso seco celular. Alíquotas de cultivo foram coletadas, centrifugadas (15 min / $3500 \mathrm{rpm})$, lavadas com água destilada e novamente centrifugadas. A massa depositada ficou em estufa a vácuo a $75{ }^{\circ} \mathrm{C}$ até atingir peso constante. Todos dados determinados experimentalmente foram expressos como a média das duplicatas, com a indicação dos respectivos desvios padrão.

Coeficiente volumétrico de transferência de oxigênio: Para determinação experimental dos valores de $k_{L} a$ e da taxa de respiração celular (OUR) utilizou-se o método dinâmico, amplamente empregado em cultivos em razão de sua praticidade, reprodutibilidade e relativa acurácia (GarciaOchoa e Gomez, 2009). O método foi proposto por Bandyopadhyay e Humphrey (1967) e descrito com detalhes por Borzani et al (2001). A técnica original envolve a breve interrupção da aeração e da agitação no biorreator. Empregando-se a modificação descrita por Pouliot et al. (2000), a agitação foi reduzida a $50 \mathrm{rpm}$ e não totalmente interrompida, a fim de impedir a decantação das células e, assim, garantir a obtenção de medidas corretas pelo eletrodo de oxigênio. A taxa específica de respiração $\left(q_{\mathrm{O} 2}\right)$ foi determinada pela razão entre a OUR e biomassa. A medida do $k_{L} a$ do biorreator sem células, quando ainda não há consumo biológico de oxigênio, foi feita pelo método dinâmico gassing-out (Riet, 1979), expulsando-se o gás através da injeção de nitrogênio.

Análise estatística: Os dados experimentais foram submetidos à análise de variância para investigar se os valores de $k_{L} a$ foram significativamente afetados durante o tempo de cultivo. Utilizou-se a ferramenta de análise de dados ANOVA: fator único do MSExcel 2007 (Microsoft). 


\section{RESULTADOS E DISCUSSÃO}

\subsection{Crescimento celular e consumo de oxigênio}

Ao longo das $12 \mathrm{~h}$ de cultivo, observou-se alteração no seu aspecto visual de transparente para rosa leitoso, acompanhado de odor característico. A atividade metabólica celular foi investigada através da curva característica de crescimento celular e de $q_{\mathrm{O} 2}$ (Figura 1). Conforme a curva de crescimento, observou-se ausência de fase lag de adaptação das células ao biorreator, uma vez que o inóculo foi cultivado previamente no mesmo meio de cultivo e, ao ser introduzido no biorreator, já se encontrava na fase exponencial de crescimento. $\mathrm{O}$ valor máximo de $q_{\mathrm{O} 2}$ foi registrado no início do cultivo, quando as células estavam no início da fase de crescimento exponencial. Com o aumento gradual de biomassa e a consequente provável limitação de nutrientes, o cultivo se aproxima de uma fase estacionária, momento em que ocorre a redução progressiva da atividade metabólica e do $q_{\mathrm{O} 2}$.
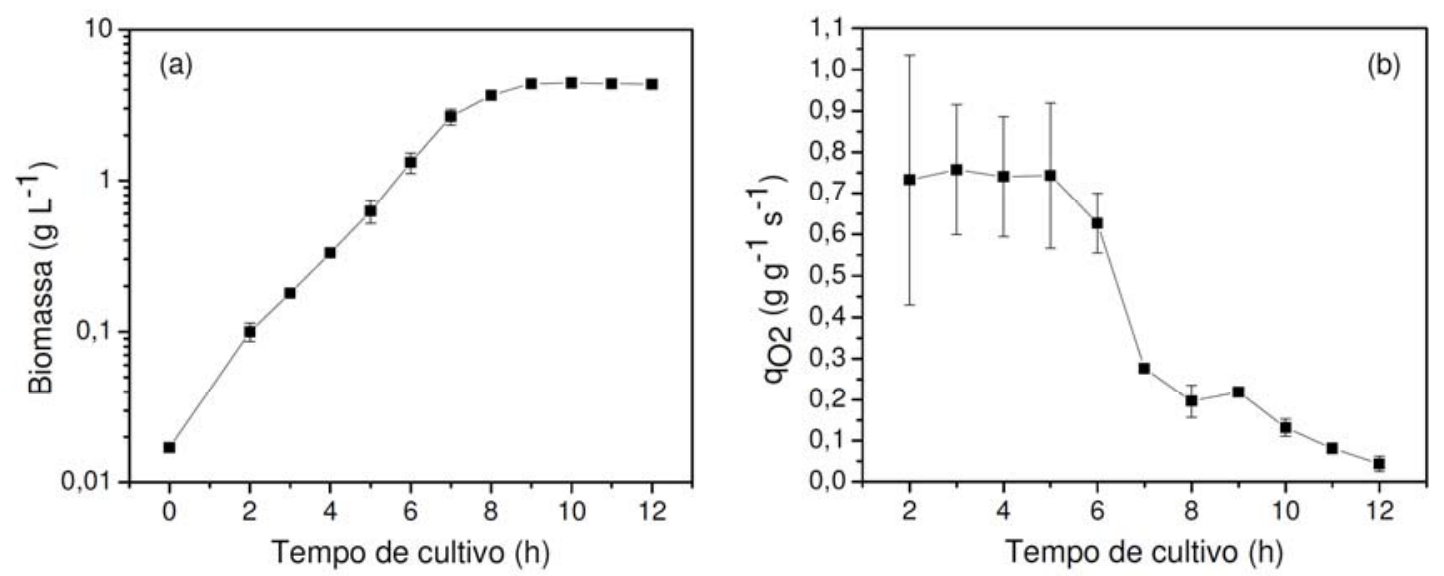

Figura 1 - Curvas de (a) crescimento celular e (b) taxa de respiração específica para cultivo de $B$. megaterium. As barras verticais indicam o desvio padrão entre os valores médios das duplicatas.

A análise conjunta das curvas de biomassa total e $q_{\mathrm{O} 2}$ permite perceber o início de uma leve desaceleração do crescimento celular em $6 \mathrm{~h}$ de cultivo, tornando-se clara a desaceleração a partir de $7 \mathrm{~h}$ e, em aproximadamente $9 \mathrm{~h}$, o crescimento encontra-se já em uma fase plenamente estacionária.

\subsection{Balanço de massa para o oxigênio: perfil de $p_{\mathrm{O} 2}$ e OUR}

$\mathrm{O}$ balanço material para o oxigênio em um biorreator aeróbio é dado pela diferença entre o oxigênio transferido ao meio e o consumido pelas células (OUR). Portanto, as curvas de $p_{\mathrm{O} 2}$ e de OUR (Figura 2) apresentam comportamentos contrários, sendo a queda no $p_{\mathrm{O} 2}$ causada pela respiração celular. Assim como a curva de $q_{\mathrm{O} 2}$ e biomassa, as curvas de $p_{\mathrm{O} 2}$ e de OUR estão interrelacionadas e apresentaram a evolução típica para cultivos aeróbios descrita por Garcia-Ochoa et al. (2010). 

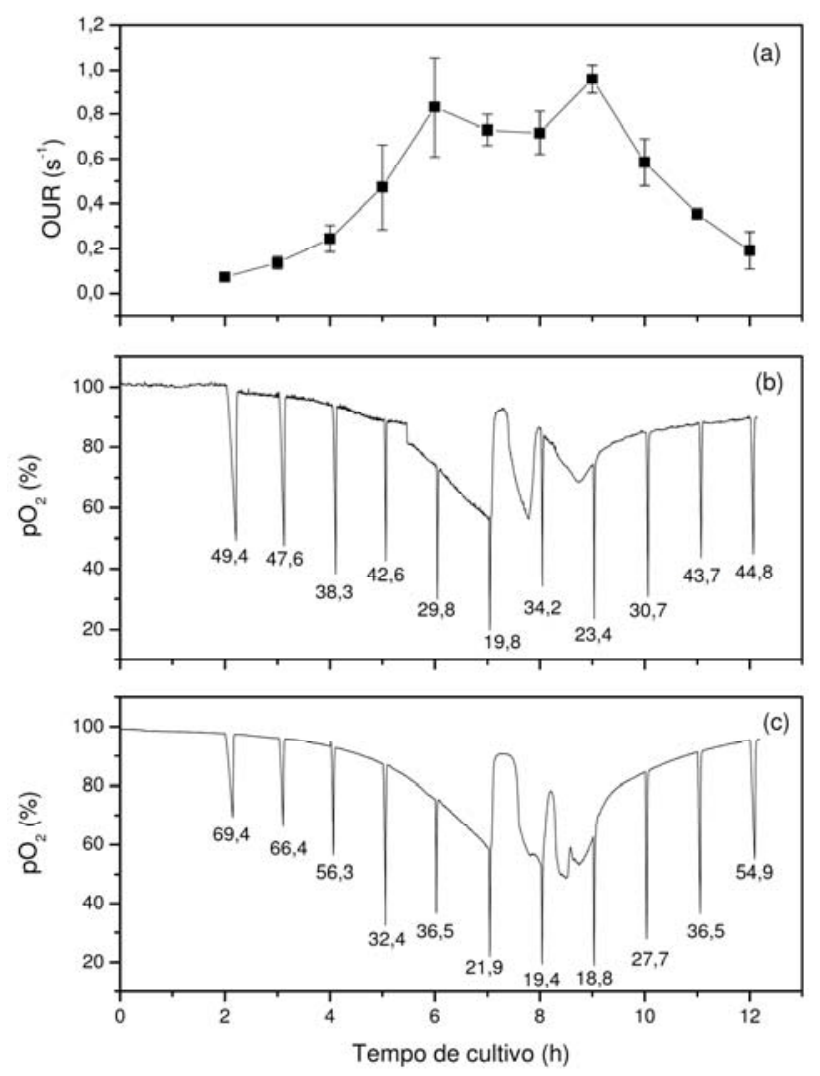

Figura 2 - Perfil da (a) taxa de respiração celular, (b) percentual de oxigênio dissolvido no cultivo de B. megaterium e (c) na sua duplicata.

De maneira geral, o aumento gradual da biomassa observado na fase exponencial de crescimento na Figura 1, com consequente aumento do consumo de substrato e da demanda de oxigênio (indicado pelo crescimento da OUR na Figura 2), provocou uma queda da concentração de oxigênio dissolvido no meio. Posteriormente, com a limitação de nutrientes, entre eles o oxigênio, as células ingressaram na fase estacionária e a demanda pelo gás diminuiu, fazendo com que os níveis de oxigênio no meio fossem recuperados. As quedas periódicas acentuadas nas curvas de $p_{\mathrm{O} 2}$ correspondem às determinações de $k_{L} a$ através do método dinâmico para o biorreator com células. Já a queda inesperada, em $7 \mathrm{~h}$ e $8 \mathrm{~h}$, na curva de OUR e a consequente elevação abrupta, nesses mesmos momentos, nas curvas de $p_{\mathrm{O} 2}$, indicam um comportamento anômalo.

Acredita-se que, a $7 \mathrm{~h}$ e $8 \mathrm{~h}$, a concentração de oxigênio tenha caído abaixo do valor da concentração crítica para $B$. megaterium, definida como o valor acima do qual a velocidade específica de respiração $\left(q_{\mathrm{O} 2}\right)$ é constante e máxima (Borzani et al, 2001). Nesses momentos do cultivo, a OUR - produto entre biomassa e $q_{\mathrm{O} 2}$ - estaria em seus valores máximos e, com essa alta demanda de oxigênio, a aplicação do método dinâmico causou uma grande queda no $p_{\mathrm{O} 2}$, superior ao tempo de resposta do eletrodo, que continuou caindo mesmo após a retomada da 


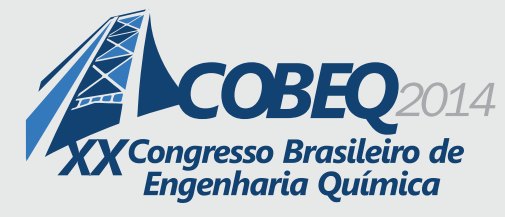

agitação e da aeração. As células, então, teriam alterado seu metabolismo para se adaptarem a um cenário de limitação de oxigênio, passando a consumir o gás a menores taxas, conforme demonstra a queda na OUR a $7 \mathrm{~h}$ e $8 \mathrm{~h}$. Essa diminuição da demanda aumentou repentinamente a disponibilidade de oxigênio no meio $\left(p_{\mathrm{O} 2}\right)$, de acordo com o balanço de massa. A partir de $9 \mathrm{~h}, \mathrm{o}$ metabolismo pareceu restabelecer seu comportamento típico. De fato, conforme Pouliot et al. (2000), se a atividade da reação bioquímica for alta o suficiente para reduzir significativamente os níveis de oxigênio dissolvido no cultivo, a determinação pelo método dinâmico torna-se inviável, devendo-se utilizar determinações baseadas em balanço de gás. Da mesma forma, Borzani et al. (2001) afirmam que para aplicação do método dinâmico, deve-se contar com uma concentração de oxigênio dissolvido relativamente alta, evitando o risco de que ela caia abaixo da crítica, de modo a manter constante o valor de $\mathrm{q}_{\mathrm{O} 2}$ das células.

Tal alteração, entretanto, permitiu obter uma estimativa preliminar do valor de concentração crítica para B. megaterium. Conforme a Figura 2, que aponta as concentrações mínimas de $\mathrm{p}_{\mathrm{O} 2}$ medidas em cada hora, acredita-se que a concentração crítica esteja ao redor dos $20 \%$, uma vez que, em $7 \mathrm{~h}$, as concentrações mínimas foram de 19,8 \% para o cultivo e de 21,9 $\%$ para sua duplicata, após as quais as bactérias apresentaram o comportamento anômalo.

\subsection{Influência da biomassa no $k_{L} a$}

No experimento, procurou-se manter as condições operacionais descritas sem alterações, de modo que apenas a biomassa afetasse os valores de $k_{L} a$. A Figura 3 apresenta os resultados obtidos para o $k_{L} a$. Foram desconsiderados os valores a $7 \mathrm{~h}$ e $8 \mathrm{~h}$ devido aos aspectos discutidos na seção anterior e à dificuldade de obtenção de um valor confiável nesses tempos.

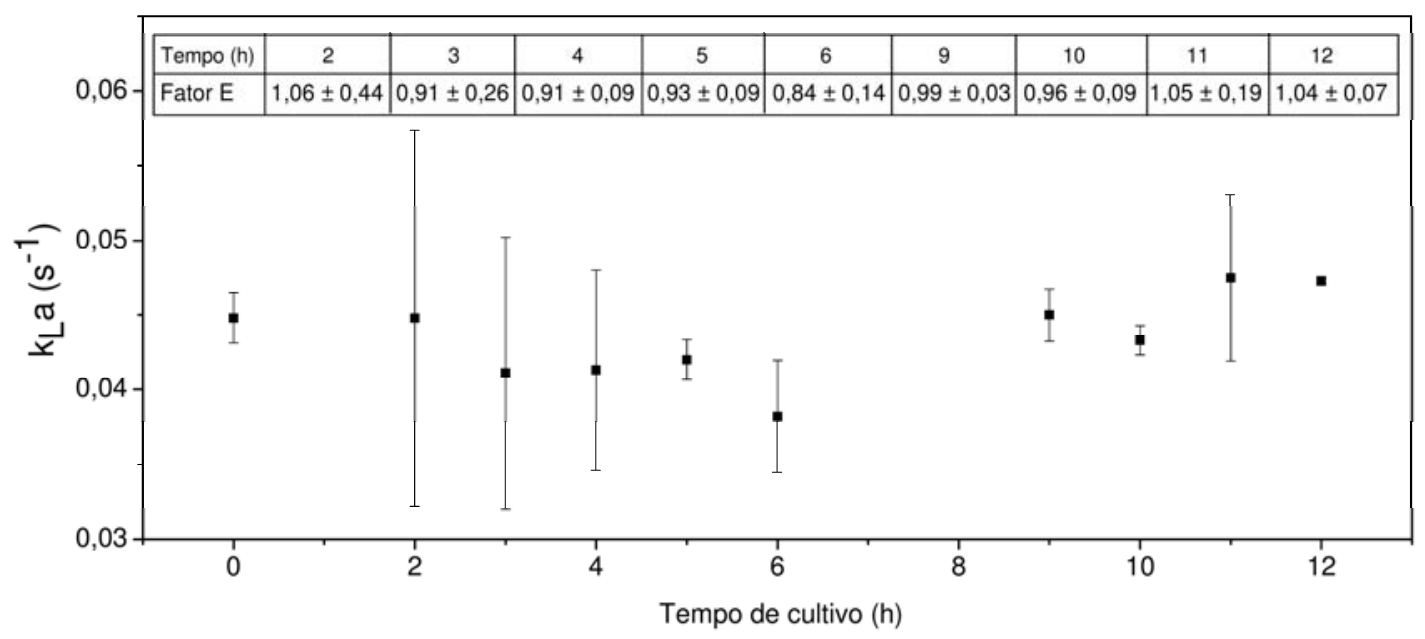

Figura 3 - Variação do $k_{L} a$ durante cultivo de Bacillus megaterium. O valor a $0 \mathrm{~h}$ corresponde à determinação para o biorreator sem células.

$\mathrm{O}$ valor médio de $k_{\mathrm{L}} a$ medido para o biorreator sem células $(0 \mathrm{~h})$ foi de $0,045 \mathrm{~s}^{-1} \pm 0,003 \mathrm{~s}^{-1}$. Esse valor manteve-se relativamente constante para o biorreator com células ao longo do cultivo, 


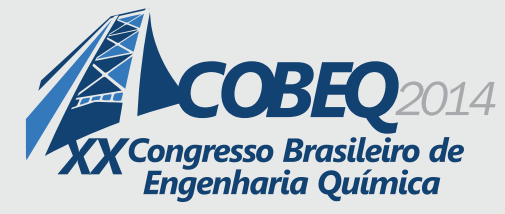

19 a 22 de outubro de 2014

Florianópolis/SC

com a quantidade de biomassa, sendo que os resultados da análise de variância mostraram que realmente não há diferença significativa entre os valores de $k_{L} a(p=0,88)$. Os desvios padrão relativamente altos entre o cultivo e sua duplicata, como se nota na Figura 3, devem-se a algumas fontes de erros desconsideradas, entre elas o tempo de resposta dinâmica do eletrodo de oxigênio dissolvido; a adição diferenciada de antiespumantes de acordo com a necessidade, os quais tendem a diminuir o $k_{L} a$ (GARCIA-OCHOA e GOMEZ, 2009); a peculiaridade dos cultivos e do metabolismo celular; e o estabelecimento manual do valor de aeração e oscilações da pressão de ar fornecido pelo compressor. Pouliot et al. (2000) observaram que erros de medida e a dinâmica do eletrodo de oxigênio afetaram o $k_{L} a$ estimado pelo método dinâmico em relação a valores obtidos por reconciliação matemática.

Os valores do fator de aumento biológico $(E)$ - razão entre os valores de $k_{L} a$ para o biorreator com células e o valor obtido inicialmente para o biorreator sem células - apresentados na Figura 3 mostram que este parâmetro pode ser considerado aproximadamente igual a 1 durante o cultivo, indicando que não há influência da presença de biomassa viável e do $q_{\mathrm{O} 2}$ no valor do $k_{L} a$. Portanto, não foi verificado o efeito da respiração celular descrito por Garcia-Ochoa e Gomez (2009), não ocorrendo aumento no $k_{L} a$. Esses resultados estão de acordo com Pouliot et al. (2000). Para esses autores, mantendo-se as demais condições experimentais constantes durante a fermentação, o $k_{L} a$ permanece relativamente inalterado para cultivos de baixa viscosidade, caso de Saccharomyces cervisiae e de B. megaterium.

Em trabalho anterior (Faccin et al., 2013), foi observado um efeito significativo da transferência de oxigênio, através de medidas do $k_{L} a$, na produção de PHB por $B$. megaterium, identificando-se um valor ótimo do coeficiente de $0,006 \mathrm{~s}^{-1} 1$ entre valores que iam de $0,002 \mathrm{~s}^{-1}$ a $0,037 \mathrm{~s}^{-1}$. Com isso, a atual constatação de que o $k_{L} a$ pode ser mantido constante durante o cultivo permite a otimização da produção de PHB através da prévia escolha desse valor e de sua manutenção ao longo do processo.

\section{CONCLUSÕES}

No presente estudo, o $k_{L} a$ - importante fator de dimensionamento em biorreatores aeróbios - não mostrou variação significativa com a presença de biomassa ativa durante um cultivo batelada de Bacillus megaterium. Com isso, elimina-se um parâmetro (biomassa) a ser ajustado em correlações para predição do coeficiente nesse sistema.

Esse resultado constitui vantagem nos estudos com B. megaterium, pois possibilita o estabelecimento prévio ao cultivo, para o biorreator sem células, e a manutenção de um valor de $k_{L} a$ ao longo do processo em que as demais condições operacionais (taxa de aeração, agitação e temperatura) sejam mantidas inalteradas. $\mathrm{O}$ valor a ser escolhido poderá ser o mais apropriado para otimizar os resultados que dependam da transferência de oxigênio, como a produção de PHB. Ainda, torna-se possível evitar a determinação do $k_{L} a$ durante o cultivo com células e os inconvenientes relacionados, tendo o método dinâmico se mostrado inaplicável durante períodos com grandes taxas de respiração. 


\section{REFERÊNCIAS}

BANDYOPADHYAY, B.; HUMPHREY, A. E. Dynamic Measurement of the Volumetric Oxygen Transfer Coefficient in Fermentation Systems. Biotechnol. Bioeng., v. 9, p. 533544, 1967.

BORZANI, W.; SCHMIDELL, W.; LIMA, U. D. A.; AQUARONE, E. Biotecnologia Industrial: fundamentos. São Paulo: Blucher, 2001.

FACCIN, D. J. L., RECH, R., SECCHI, A. R., CARDOZO, N. S. M., AYUB, M. A. Z. Influence of oxygen transfer rate on the accumulation of poly(3-hydroxybutyrate) by Bacillus megaterium, Process Biochem., v. 48, p. 420-425, 2013.

GALACTION, A.-I.; ONISCU, C.; CASCAVAL, D. Studies on Oxygen Mass Transfer in Stirred Bioreactors. Chem. Ind., v. 57, p. 276-287, 2003.

GARCIA-OCHOA, F.; GOMEZ, E. Bioreactor scale-up and oxygen transfer rate in microbial processes: An overview. Biotech. Adv., v. 27, p. 153-176, 2009.

GARCIA-OCHOA, F.; GOMEZ, E.; SANTOS, V. E.; MERCHUK, J. C. Oxygen uptake rate in microbial processes: An overview. Biochem. Eng. J., v. 49, p. 289-307, 2010.

JU, L.-K.; SUNDARARAJAN, A. The effects of cells on oxygen transfer in bioreactors: physical presence of cells as solid particles. Chem. Eng. J., v. 56, p. B15-B21, 1994.

MACRAE, R. M.; WILKINSON, J. F. Poly +hyroxybutyrate Metabolism in Washed Suspensions of Bacillus cereus and Bacillus megaterium. J. Gen. Microbiol., v. 19, p. 210 222, 1958.

POULIOT, K.; THIBAULT, J.; GARNIER, A.; LEIVA, G. A. $\mathrm{K}_{\mathrm{L}}$ a Evaluation during the course of fermentation using data reconciliation techniques. Bioprocess Eng., v. 23, p. 565-573, 2000.

REYES, G. D.; SO, R. S.; ULEP, M. M. Isolation, screening and identification of bacteria for poly- $\beta$-hydroxybutyrate (PHB) production. Stud. Environ. Sci., v. 66, p. 737-748, 1997.

VERLINDEN, R. A. J.; HILL, D. J.; KENWARD, M. A.; WILLIAM, C. D.; RADECKA, I. Bacterial synthesis of biodegradable polyhydroxyalkanoates. J. Appl. Microbiol., v. 102, p. 1437-1449, 2007.

WANG, F.; LEE, S. Y. Poly(3-Hydroxybutyrate) Production with High Productivity and High Polymer Content by a Fed-Batch Culture of Alcaligenes latus under Nitrogen Limitation. Appl. Environ. Microbiol., v. 63, p. 3703-3706, 1997.

WU, Q.; HUANG, H.; HU, G.; CHEN, J.; HO, K.; CHEN, G.-Q. Production of poly-3hydroxybutyrate by Bacillus sp. JMa5 cultivated in molasses media. Antonie van Leeuwenhoek, v. 80, p. 111-118, 2001. 